\title{
PENINGKATAN KUALITAS MAKANAN RINGAN DENGAN METODE DEEP FRYER ELECTRIC PADA KELOMPOK USAHA MIKRO DI DESA PASIRAN KECAMATAN BANTAN-BENGKALIS
}

\section{IMPROVED SNACKS QUALITY USING DEEP FRYER ELECTRIC METHOD IN MICRO BUSINESS GROUP IN PASIRAN VILLAGE BANTAN SUB-DISTRICT BENGKALIS DISTRICT}

\author{
M. Nur Faizi \& Muharnis \\ Teknik Elektronika, Teknik Elektro, Politeknik Negeri Bengkalis, Indonesia \\ ${ }^{1}$ faizi@polbeng.ac.id, ${ }^{2}$ muharnis@polbeng.ac.id
}

\begin{abstract}
Abstrak
Tujuan dari kegiatan pengabdian kepada masyarakat ini adalah untuk meningkatkan kualitas produksi gorengan yang lebih renyah dan lezat untuk memenuhi kebutuhan masyarakat dalam membeli gorengan sehingga membantu kelompok usaha mikro makanan ringan dalam memproduksi gorengannya dan meningkatkan omset penjualan. Target khusus yang telah dicapai dalam kegiatan pengabdian ini adalah sosialisasi penggunaan Deep Fryer Electric yang ramah lingkungan sebagai media penggorengan untuk meningkatkan kualitas makanan. Metode yang dilaksanakan adalah membuat sistem penggorengan dengan menggunakan sebuah mesin penggorengan elektrik (Deep Fryer Electric) yang terbuat dari Stainles Steel dengan komponen utama adalah elemen pemanas yang bersumber dari listrik dan dilengkapi dengan Thermostat (60-200 derajat celcius) sehingga dengan pengaturan ini memungkinkan proses penggorengan tanpa harus mengalami gosong pada makanan ringan tersebut dengan menggunakan metode penggorengan deep fryer electric dapat meminimalkan lama waktu penggorengan sekitar 40 detik dan produk yang dihasilkan berkualitas dibandingkan dengan penggorengan konvensional. Selain di kelompok usaha mikro, metode penggorengan ini sangat cocok diterapkan di kelompok usaha lainnya karena metode ini bersifat ramah lingkungan.
\end{abstract}

Kata Kunci: Stainlies Steel, Deep Fryer Electric, Penggorengan

\begin{abstract}
The purpose of this community service is to improve the quality of crispy and delicious fried food production to meet the needs of the community in buying fried foods, helping the micro-snack business group to produce fried foods and increase sales turnover. The specific target that has been achieved in this activity is the dissemination of the use of Deep Fryer Electric which is environmentally friendly as a frying medium to improve food quality. The method implemented is to make a frying system using an electric frying machine (Deep Fryer Electric) made of Stainless Steel with the main component being heating elements sourced from electricity and equipped with a Thermostat (100 - 300 degrees Celsius) so that this arrangement allows the process frying without having to burn with a deep fryer electric frying method can minimize the frying time by about 40 seconds and the product produced is of a quality compared to conventional frying pans.
\end{abstract}

Keywords: Stainless Steel, Deep Fryer Electric, Frying

\section{PENDAHULUAN}

Makanan diperlukan untuk mempertahankan kehidupan manusia. Makanan berasal dari bahan pangan yang sudah atau tanpa mengalami pengolahan. Pangan adalah semua produk yang dikonsumsi manusia baik dalam bentuk bahan mentah, setengah jadi atau jadi, yang meliputi 
produk-produk industri, restoran, serta makanan tradisional atau jajanan (Afrianti, 2008). Di era yang modern seperti saat ini telah banyak inovasi makanan, salah satunya adalah makanan beku (frozeen food) yang bahan utamanya adalah daging. Salah satu dari makanan beku itu adalah Sosis. Sosis dapat dikonsumsi melalui proses penggorengan.

Penggorengan merupakan salah satu metode tertua dan paling umum dalam teknik persiapan makanan. Penggorengan dengan minyak atau lemak lebih banyak dipilih sebagai cara pengolahan makanan karena mampu meningkatkan citarasa dan tekstur bahan pangan yang spesifik sehingga bahan pangan menjadi kenyal dan renyah dengan warna yang diinginkan. Hal tersebut membuat produk pangan yang diolah dengan cara digoreng sangat digemari, tidak hanya di Indonesia namun juga di seluruh dunia. Penggorengan dilakukan dengan memasukkan makanan dalam minyak panas dengan kontak antara minyak, udara, dan makanan pada suhu $150^{\circ} \mathrm{C}$ hingga $190^{\circ} \mathrm{C}$. Minyak goreng bertindak sebagai media perpindahan panas dan berkontribusi terhadap tekstur dan rasa makanan yang digoreng.

Terjadinya perpindahan panas dan massa minyak, makanan, dan udara selama penggorengan menghasilkan kualitas yang diinginkan dari makanan yang digoreng. Berdasarkan hasil pantauan di lapangan terdapat 1 unit penggorengan konvensional yang menggunakan wajan sebagai media penggorengan dan kompor gas sebagai media pemanas yang bersumber dari LPG. Pada proses penggorengan ini harus benar-benar dijaga agar produk yang digoreng tidak gosong. Namun hasil dari penggorengan ini tidak optimal dikarenakan produk terlalu lama kontak dengan minyak goreng dan temperatur tidak stabil atau panasnya tidak merata hal ini berdampak pada tekstur yang kurang menarik pada produk sehingga warna, aroma dan rasa produk tersebut kurang lezat. Gambar 1 memperlihatkan alat penggorengan konvensional.

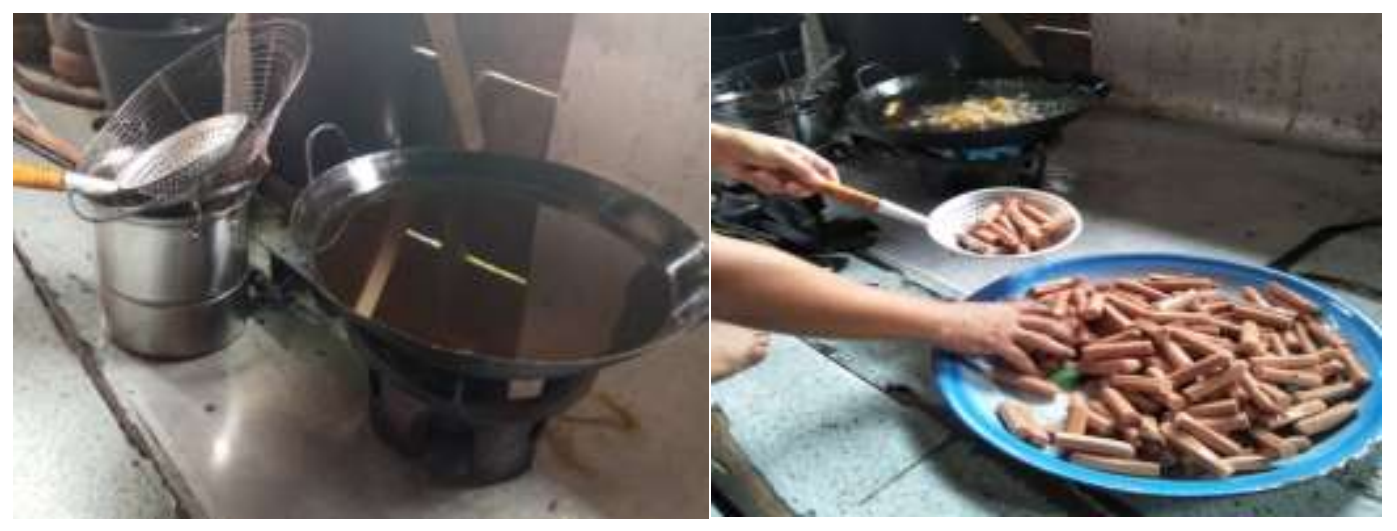

Figur 1. Foto Alat Penggorengan Konvensional 


\section{METODOLOGI}

\section{Metode Pelaksanaan}

Bagan alir pencapaian tujuan dalam kegiatan Pengabdian PNBP Polbeng ini dapat dilihat pada Gambar 2 berikut.

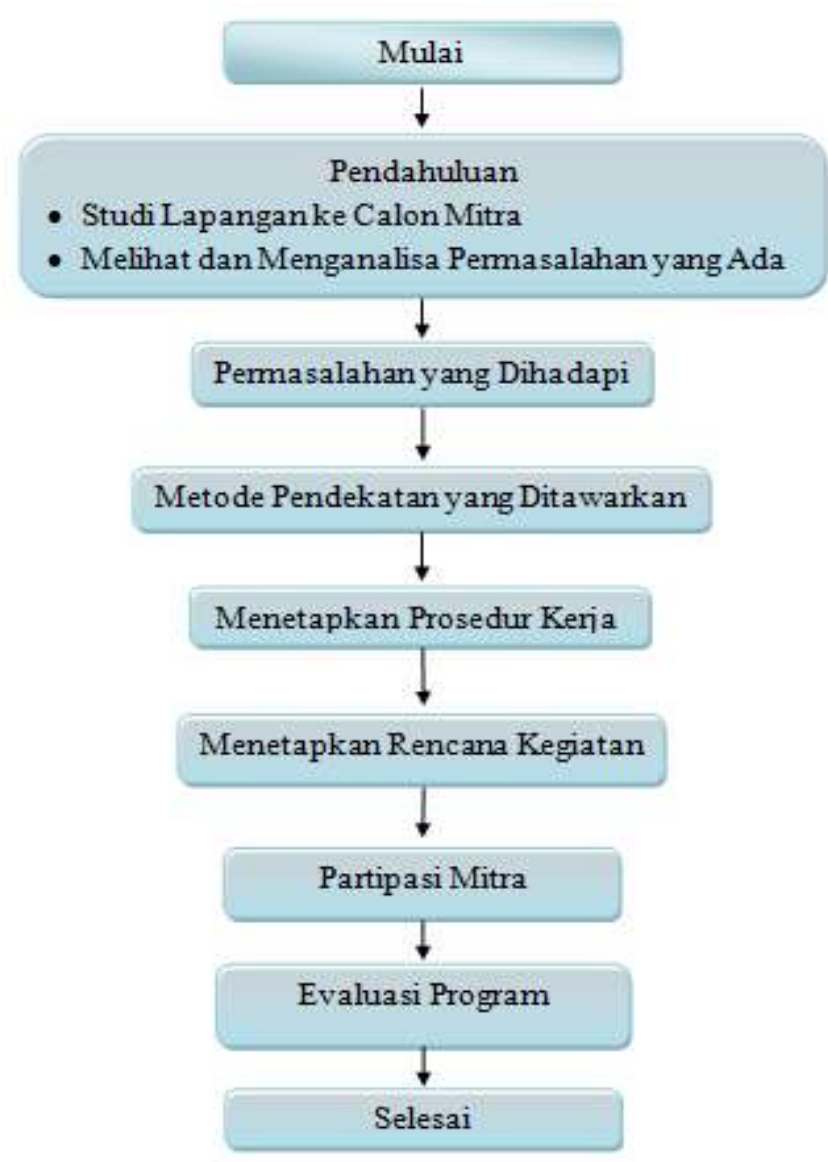

Figur 2. Alur Kerja Program Yang Laksanakan

\section{Solusi dan Target}

Solusi yang dapat dimanfaatkan dengan biaya operasianal yang murah adalah pembuatan mesin penggorengan elektrik yang terbuat dari bahan stainless steel. Mesin penggorengan elektrik ini menggunakan elemen pemanas stainless steel dengan efisiensi tinggi dan tahan korosi, dilengkapi dengan thermostat untuk mengontrol temperatur dengan cara mendeteksi dan koreksi error sehingga mudah digunakan dalam mengatur suhu penggorengan untuk menghasilakan gorengan yang sempurna. Pada mesin penggorengan elektrik ini dilengkapi dengan filter yang berfungsi untuk memisahkan limbah dari penggorengan sehingga minyak goreng lebih tahan lama karena ampas tidak berada diatas api. 
Produk yang dirancang dan akan dibuat pada pengabdian ini dapat dilihat pada Gambar 3 berikut ini.

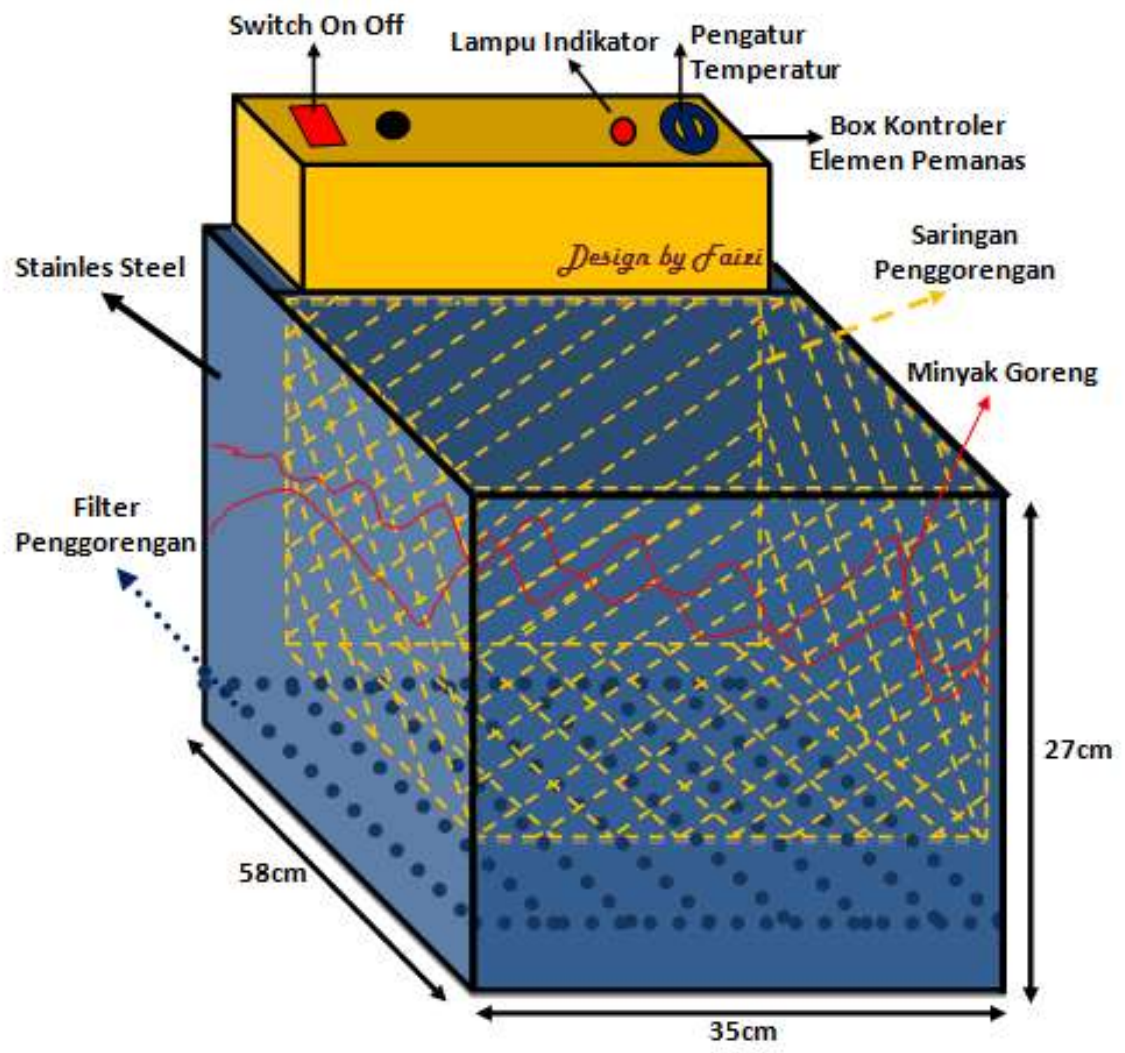

Figur 3. Foto Desain Mesin Penggorengan Elektrik (Deep Fryer Electric)

Target luaran yang akan dicapai dalam pelaksanaan Pengabdian PNBP Polbeng adalah sebuah produk yang dapat dimanfaatkan oleh kelompok usaha mikro makanan ringan sebagai peningkatan mutu penjualan produk gorengan. IbM ini akan meningkatkan keuntungan dari penjualan hasil gorengan yang memiliki warna, aroma, tekstur serta rasa yang lezat dan enak sehingga digemari hampir semua orang.

\section{PEMBAHASAN}

Kegiatan pengabdian ini dilaksanakan di kediaman mitra yang beralamat di jalan rajimun desa pasiran kecamatan bantan. Beberapa kegaitan dilakukan untuk mengetahui tingkat keberhasilan sebuah produk yang akan dijajakan. Mulai dari uji coba alat guna untuk mengetahui kinerja mesin penggorengan elektrik ini berjalan dengan baik. Gambar 4 merupakan deep fryer electric yang digunakan pada pengabdian ini. 


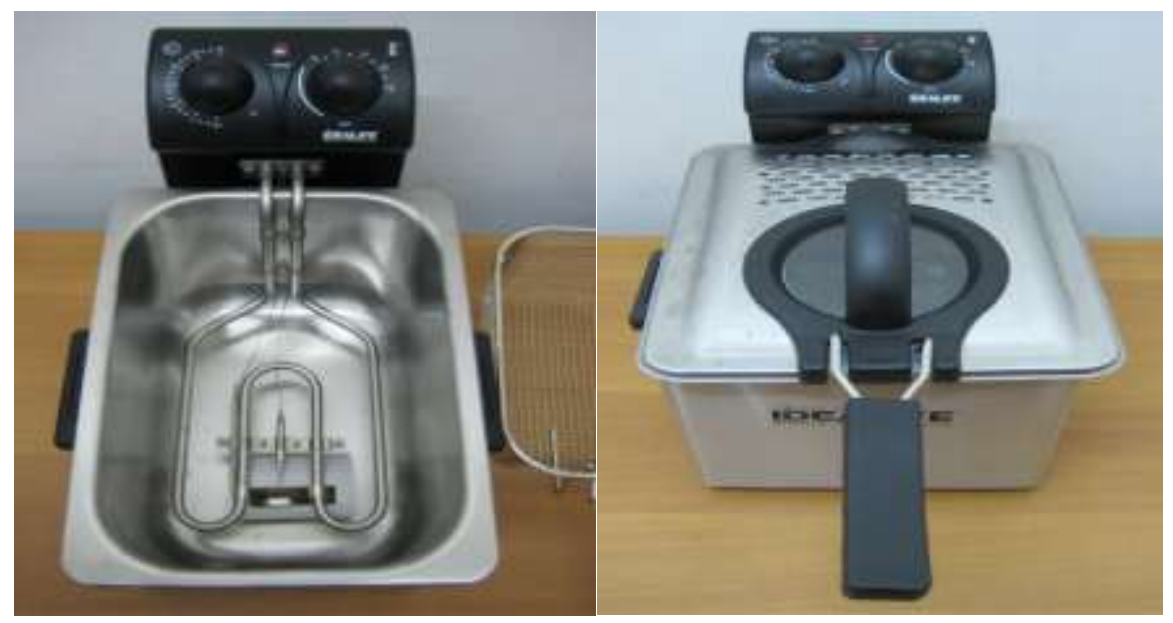

Figur 4. Foto Deep Fryer Electric

Penggorengan Elektrik ini memiliki bentuk yang lebih cekung kedalam dan dapat menampung minyak goreng hingga 6 liter. deep fryer electrik ini juga dilengkapi dengan fitur Thermostat Control atau Pengatur Suhu yang akan sangat membantu anda dalam mengontrol suhu saat menggoreng masakan dengan suhu yang dibutuhkan. Di mana pengaturan ini memungkinkan proses memasak tanpa harus mengalami gosong. Pada pengabdian ini dilakukan beberapa proses penggorengan dengan berbagai metode mulai dari penggorengan menggunakan media konvensional sampai dengan menggunakan media deep fryer. Hal ini dilakukan untuk mengetahui hasil produk yang dihasilkan. Ketika menggunakan media penggorengan konvensional (wajan) dengan jumlah takaran minyak goreng yang sama yaitu 2 liter hasilnya berbeda dengan menggunakan media penggorengan deep fryer. Hasil penggorengan dari dua cara tersebut ditunjukkan pada Gambar 5 berikut ini.

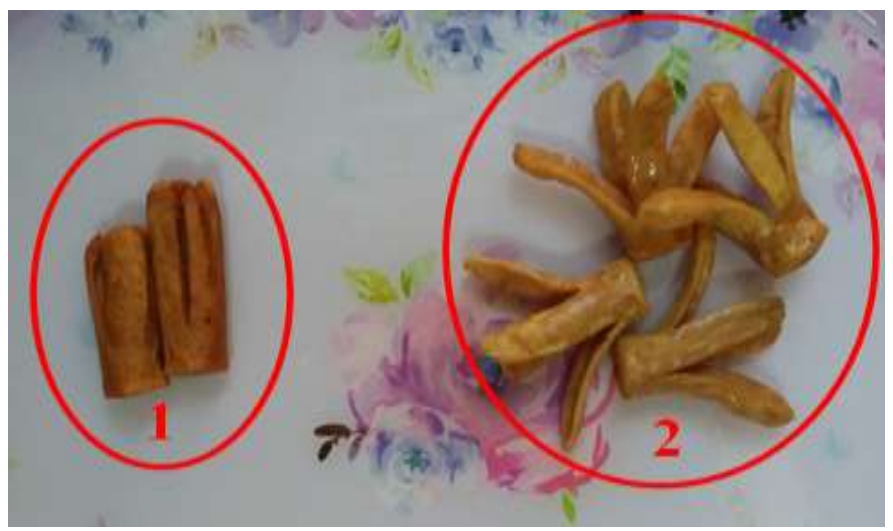

Figur 5. Foto Hasil Penggorengan Konvensional dan Deep Frayer Electric 
Dari Gambar 5. dapat dijelaskan bahwa produk yang digunakan sebagai bahan pengujian adalah sosis ayam. Dapat dilihat bahwa hasil produk 1 dan produk 2 terdapat perbedaan yang signifikan yang dapat dijelaskan pada Tabel 1 dan 2 berikut ini.

Tabel.1. Hasil Pengujian Media Konvensiaonal (wajan)

\begin{tabular}{|c|c|c|c|c|c|}
\hline Waktu & Warna & Bentuk & Rasa & Kerenyahan & Aroma \\
\hline 20 Detik & Normal Sosis & $\begin{array}{l}\text { Tidak } \\
\text { Mekar }\end{array}$ & Gurih & $\begin{array}{l}\text { Tidak } \\
\text { Renyah }\end{array}$ & Normal \\
\hline 40 Detik & $\begin{array}{l}\text { Kuning } \\
\text { Keemasan }\end{array}$ & $\begin{array}{l}\text { Tidak } \\
\text { Mekar }\end{array}$ & Gurih & $\begin{array}{l}\text { Tidak } \\
\text { Renyah }\end{array}$ & Normal \\
\hline 60 Detik & $\begin{array}{l}\text { Kuning } \\
\text { Kecoklatan }\end{array}$ & $\begin{array}{l}\text { Tidak } \\
\text { Mekar }\end{array}$ & Gurih & $\begin{array}{l}\text { Tidak } \\
\text { Renyah }\end{array}$ & $\begin{array}{l}\text { Agak } \\
\text { Gosong }\end{array}$ \\
\hline
\end{tabular}

Tabel.2. Hasil Pengujian Media Deep Fayer Electric

\begin{tabular}{llllll}
\hline \multicolumn{1}{c}{ Waktu } & Warna & Bentuk & Rasa & Kerenyahan & Aroma \\
\hline 8 Detik & $\begin{array}{l}\text { Normal } \\
\text { Sosis }\end{array}$ & Tidak Mekar & Gurih & Tidak Renyah & Normal \\
\hline 14 Detik & $\begin{array}{l}\text { Normal } \\
\text { Sosis }\end{array}$ & Mulai Mekar & Gurih & Renyah & Normal \\
\hline 20 Detik & $\begin{array}{l}\text { Kuning } \\
\text { Keemasan }\end{array}$ & Mekar & Gurih & Renyah & Normal \\
\hline
\end{tabular}

Dari Tabel 1 dan 2 dapat disimpulkan bahwa penggunaan deep fryer dapat menghemat waktu serta produk yang dihasilkan lebih berkualitas dan teksturnya menarik. Sehingga dengan cara ini dapat meningkatkan kualitas makanan ringan dan dapat meningkatkan omset penjualan.

\section{KESIMPULAN DAN SARAN}

Dengan menggunakan metode penggorengan deep fryer electric dapat meminimalkan lama waktu penggorengan sekitar 40 detik dan produk yang dihasilkan berkualitas dibandingkan dengan penggorengan konvensional. Selain di kelompok usaha mikro, metode penggorengan ini sangat cocok diterapkan di kelompok usaha lainnya karena metode ini bersifat ramah lingkungan.

Dikarenakan sumber penggorengan ini bersumber dari listrik (PLN) dan kelompok usaha mikro hanya mengandalkan keuntungan dari penjualan produk maka perlu sumber 
energi alternatif lainnya hal ini disarankan karena tarif listrik yang sampai saat ini mengalami kenaikkan.

\section{REFERENSI}

Andarwulan, N.,Y.T. Sadikin dan F. G. Winarno., 1997. "Pengaruh Lama Penggorengan dan Penggunaan Adsorben Terhadap Mutu Minyak Goreng Bekas Penggorengan TahuTempe".

Harsman T. 2008. "Desain dan Uji Penggoreng Open Deep Frying dengan Perubahan Posisi Elemen Pemanas” Institut Pertanian Bogor, Bogor.

Husnah S., Jaya A. I., Ratianingsih R. 2016 "Mengefisiensikan Penggunaan Energi Listrik: Studi Kasus Pada Model Aliran Panas Pada Water Cooker (Pemanas Air Elektrik)". JIMT, Vol. 13 ( 1): 118 - 127).

Ketaren, S., 2008. “Minyak dan Lemak Pangan”. Penerbit Universitas Indonesia, Jakarta.

Prasetyawan, E.A. 2007. "Uji Kualitas Minyak Goreng Pada Para Penjual Gorengan di lingkungan Kampus Universitas Jember" Jember.

Ryadin, A.U. 2017. "Sosialisasi dan Penyuluhan Kesehatan Masyarakat di RW 19 Kelurahan Tanjung Uncang” Minda Baharu, Vol. 1 (1): 1-6

Sartika, D.R.A. 2009.’Pengaruh Suhu dan Lama Proses Menggoreng (deep frying) Terhadap Pembentukan Asam Lemak Trans" Makara, Sains Vol 13(1): 23 - 28.

Winarno, F.G. 1999. "Minyak Goreng Dalam Menu Masyarakat” Pusbangtepa IPB.Bogor. 